\title{
Identifying Youth with Anxiety Disorders in Pediatric Primary Care Setting: A Preliminary Report from Thailand
}

\section{Sirirat Ularntinon ( $\nabla$ siriratul@gmail.com )}

Queen Sirikit National Institute of Child Health https://orcid.org/0000-0002-8630-7673 Jinjutha Nithiuthai

Queen Sirikit National Institute of Child Health

\section{Research article}

Keywords: anxiety, pediatric primary care, somatic, unexplained physical symptom

Posted Date: March 8th, 2022

DOI: https://doi.org/10.21203/rs.3.rs-1063867/v1

License: (c) (i) This work is licensed under a Creative Commons Attribution 4.0 International License.

Read Full License 


\section{Abstract}

Background. Non-specific somatic symptoms are common chief complaints among the youths who have anxiety disorders, particularly in non-Western countries where childhood mental health needs are underrecognized. Screening for the youths at risk of anxiety disorders in pediatric medical setting, then can be an ample opportunity to identify this most prevalent but under-diagnosed mental health problem. Therefore, this study aims to determine the possibility of identifying the youths at risk of having anxiety disorders who visited a pediatric primary care clinic for the examination of physical symptoms in Thailand.

Methods. The Screen for Child Anxiety and Related Emotional Disorders (SCARED - Thai Version), including youth self-report and parent forms, were completed by 92 pairs of youths and

their parents. Data regarding associated factors, clinical characteristics, and general health status in the past year were obtained.

Results. Anxiety disorder symptoms above the threshold for clinical diagnosis of the SCARED were identified in $39 \%$ of participants. Clinical variables associated with significantly elevated anxiety symptoms included female gender, having non-specific somatic pain as main complaints, and a number of medical visits greater than 6 times in the past year.

Conclusions. Anxiety disorder in youths is frequently under-diagnosed and un-treated, hence, becoming a hidden burden in pediatric medical setting in non-Western countries where mental health movement is still evolving. Enhancing awareness of the possibility of anxiety disorder in the youths presenting with unexplained physical complaints is a crucial step toward reducing this load of unnecessary medical health care utilization and optimizing long-term outcomes of the affected youths.

\section{Background}

As one of the most common mental health problems in children and adolescents, anxiety disorders affect approximately $5 \%-17 \%$ of the youths with the mean age of occurrence at 11 years old [1-2].

However, previous study reported that only $17 \%$ of the affected youths were able to access standard treatment [3]. Being left undiagnosed or untreated, these youths are at increasing risk of developing other psychopathologic co-morbidities including mood disorder, substance use disorder, and chronic impairment in academic, family, and social functions until adulthood [1].

Despite the relatively high prevalence of the condition reported from Western countries, there is still a dearth of studies focusing on the youths in non-Western countries, particularly the Asian countries where childhood mental health awareness is still in their conception and may have a cross-cultural variation in prevalence and measurement [4-5]. 
Previous studies from Western countries reported non-specific physical symptoms such as chest discomfort, abdominal pain, and fainting as common manifestations of childhood anxiety disorder presenting at pediatric medical care [6-10].There are also substantial research on the feasibility of using anxiety screeners in pediatric primary care in the United States [11-14].

Although previous studies from the US have demonstrated that pediatric primary care provides an ample opportunity for identifying the youths at risk of childhood anxiety disorders [15], however, primary care providers and pediatricians in Asian countries often have a limited awareness about this condition, and low availability of practical tools to help them recognize the mental health issues among the youths who mainly present with a physical complaint that shouldn't be endorsed as a medical issue, which will put a dispensable burden on primary health care utilities [16].

Enhancing the recognition of anxiety disorders in children and adolescents in medical setting could be a logical step towards the goal of early identification and intervention of this most prevalent but unrecognized and untreated childhood mental health problems, particularly in the countries with limited mental health awareness and resources.

Therefore, this current study aims to provide a preliminary report on the possibility of identifying anxiety symptoms and associated clinical variables that could be beneficial in uncovering the youths at risk of having anxiety disorders, who present with a non-psychiatric complaint at a pediatric primary care clinic in Thailand.

\section{Methods}

\section{Setting}

This study was conducted at Queen Sirikit National Institute of Child Health (QSNICH), Bangkok, Thailand. QSNICH is a major public, pediatric health service facility located in the urban area of Bangkok. The study took place at the general pediatric out-patient department of the institute. The study protocol was reviewed and approved by the Ethics committee/Institutional Review Board (IRB) of Queen Sirikit National Institute of Child Health.

\section{Participants \& Measures}

Due to the hustle and bustle nature of pediatric out-patient setting in Thailand, participants were randomly enrolled as convenient samples. The inclusion criteria were the youths aged 10-18 years who presented for an acute medical visit at primary pediatric out-patient department from 1 May 2014 to 31 October 2015.

Written informed consent and assent were obtained from the parent-child dyads. Exclusion criteria included: (1) Life threatening illness or unstable vital signs or symptoms; (2) Having any neurodevelopment or psychiatric disorder at the time of recruitment; and (3) Children or parents were unable to complete study measures and forms due to language or learning difficulties. Demographic, 
general medical, and health data were retrieved from participants' medical records by the second author who was a pediatric trainee at the time of the study period ( JN).

The Screen for Child Anxiety and Related Emotional Disorders (SCARED) was used to assess the existence and severity of anxiety disorder symptoms in child participants. SCARED is a 41-items, 3-points (0-2 from "none" to "very true") likert scale designed to screen for pediatric anxiety disorders with a reported threshold for high probability of clinical disorder at 30 from the overall score of 84 [17].

Although the subscale can be used to screen for the anxiety disorders classified in DSM-IV-TR (Diagnostic and Statistical Manual of Mental Disorders, Fourth Edition, Text Revision) which include separation anxiety disorder, panic disorder, generalized anxiety disorder, and social anxiety disorder; however, only the total score (above 30) was used to identify the at-risk participants in this current study.

The SCARED has good psychometric properties in content reliability and validity when comparing with standard psychiatric interview [18-19], and has been regarded as one of the most widely used pediatric anxiety screening measures [20]. SCARED has been translated into several languages including; Arabic[21], Chinese[22], German[23], Italian[24], Spanish[25], Portuguese [26], and Persian [27].

The SCARED - Thai Version has a good internal consistency with Cronbach's alpha at .903 which is comparable to the original English Version [18], and a fair degree of agreement between parent and child with kappa agreement at 0.405 determined from this current study. Participants who had the score above the clinical threshold would receive an educational booklet about anxiety disorders in children and adolescents by the author (JN); then undergo a formal mental health evaluation to confirm the diagnosis; and acquire appropriate intervention by the first author who is a child psychiatrist (SU).

\section{Data analyses}

Descriptive analyses and percentage were calculated for prevalence, demographic and general medical and health data. Multivariate analysis was performed to identify clinical variables

significantly associated with elevated anxiety disorder symptoms. The data was analyzed using SPSS Statistic version 17.0.

\section{Results}

\section{Demographic and health characteristics of the participants}

During the study period, 104 participants were enrolled. Of these, 12 were excluded due to incomplete data. Therefore, 92 participants were included in further analyses. Most participants (96\%) were in the age range of 10-14 years. The youngest was 10 years old at enrollment; the oldest was 16 years old; and the median age was 12 years. About one-third of them (36\%) had an underlying medical condition, most of which were well-controlled allergic rhinitis. Ninety percent of participants lived with their parents. With regard to the education of parents, $38 \%$ finished the college level and $25 \%$ finished high school. Eighty- 
three percent of parents lived together in a same household. Twenty-seven percent $(n=25)$ of child participants had physical pain including headache, stomachache and chest pain as their major symptoms for the medical visits.

Seventy-three percent $(n=67)$ had a hospital visit for some other acute illnesses such as fever and respiratory tract infection. Ninety-one percent $(n=84)$ of child participants had made at least two medical visits in the past year; and one-fourth of them $(n=21)$ had made more than six medical visits due to their acute illnesses in the past year. [Table1]

Table 1: Demographic and clinical characteristics

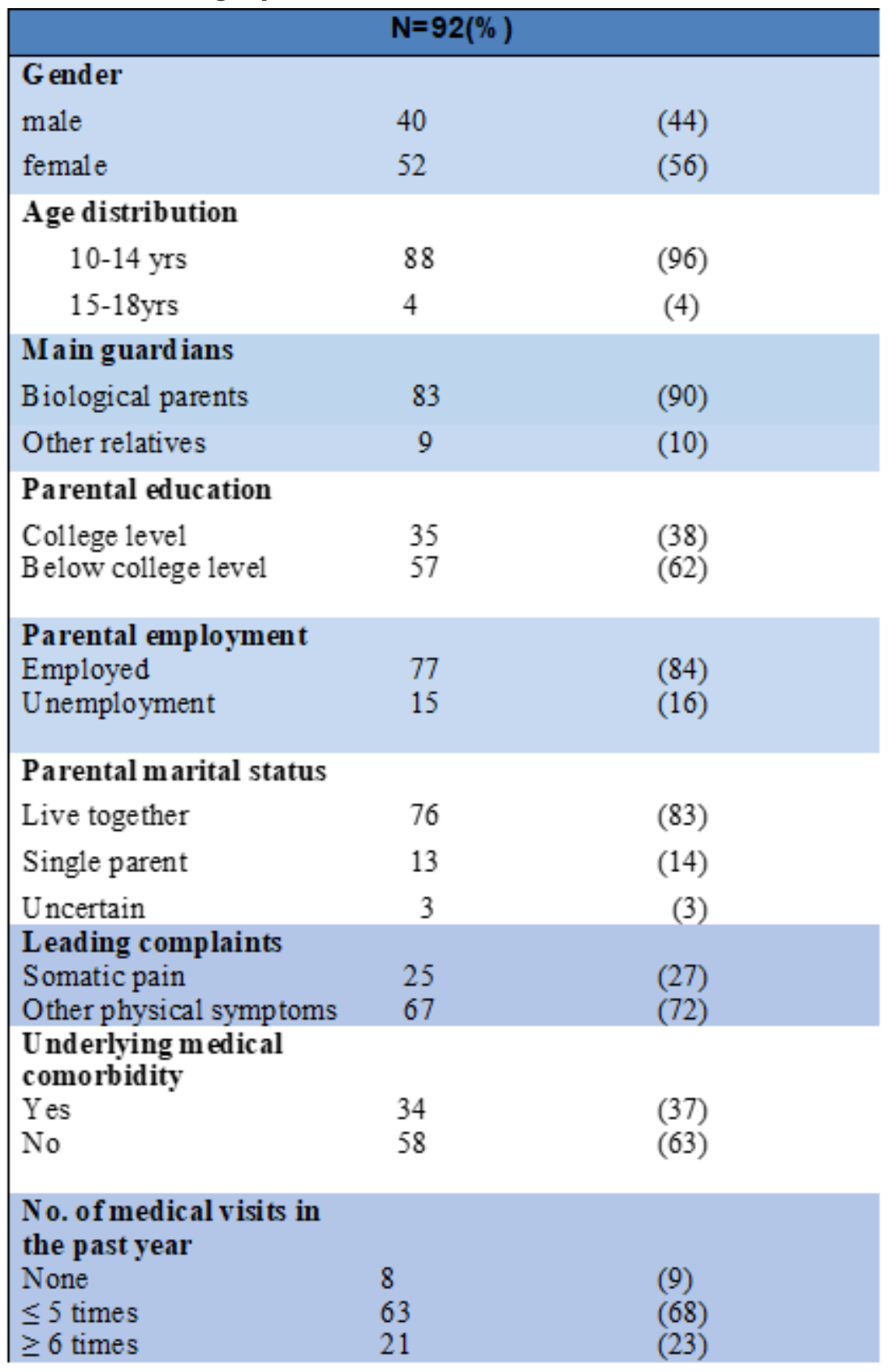

\section{Identifying anxiety symptoms and clinical disorders}


Among 92 child participants with completed forms and measures, $39 \%(n=36)$ had the overall score of the SCARED above the threshold ( $>30$ ) for high possibility of anxiety disorders diagnosis; and $39 \%$ of them (14 out of 36 ) had positive results on both the parent-report and their own self- report forms. Among 36 participants who had the SCARED score above the threshold for clinical range, after a brief discussion and receiving an educational material about anxiety in children, $39 \%(n=14)$ agreed to have an appointment for further mental health evaluation and proper intervention if required. Notably, only $25 \%$ child-only screened positive group agreed for further mental health evaluation and treatment whereas $57 \%$ of parent and child screened positive group was willing to have further management of their anxiety disorders symptoms.

\section{Associated clinical variables for above threshold anxiety disorder symptoms}

Female gender (OR=3.74, $p$-value .007) was a clinical variable independently associated with significantly elevated anxiety symptoms from child reported of their own anxiety symptoms. Having non-specific somatic pain as disabling symptoms $(\mathrm{OR}=6.23, p$-value .001) and the medical visits more than 6 times in the past year (OR=5.75, $p$-value .038) were identified from multivariate analysis as significant factors contributing to elevated anxiety symptoms shown in parent-report form for their child's anxiety symptoms. [Table 2] 
Table 2

Clinical variables associated with positive anxiety screening in pediatric primary care

\begin{tabular}{|c|c|c|c|c|c|c|}
\hline & \multicolumn{3}{|c|}{$\begin{array}{l}\text { Anxiety Screening positive by Child } \\
\text { self- report }\end{array}$} & \multicolumn{3}{|c|}{$\begin{array}{l}\text { Anxiety Screening positive by } \\
\text { Parent - report }\end{array}$} \\
\hline & $\mathrm{n}=30$ & Odds ratio & $\begin{array}{l}\text { p-value } \\
(95 \% \mathrm{Cl})\end{array}$ & $\mathrm{n}=\mathbf{2 0}$ & $\begin{array}{l}\text { Odds } \\
\text { ratio }\end{array}$ & $\begin{array}{l}\text { p value } \\
(95 \% \mathrm{Cl})\end{array}$ \\
\hline Gender & 7 & 3.74 & $0.007^{c}$ & 7 & 1.57 & $0.389^{C}$ \\
\hline Male & 23 & & $(1.40-9.99)$ & 13 & & $(0.56-4.40)$ \\
\hline \multicolumn{7}{|l|}{ Female } \\
\hline Age distribution & 28 & 2.14 & $0.594^{F}$ & 20 & NA & $0.573^{F}$ \\
\hline $10-14$ yrs & 2 & & $(0.29-16.00)$ & 0 & & \\
\hline \multicolumn{7}{|l|}{ 15-18yrs } \\
\hline Main guardians & 26 & 2.32 & $0.260^{F}$ & 19 & 0.48 & $0.680^{F}$ \\
\hline Biological parents & 4 & & $(0.54-10.02)$ & 1 & & $(0.06-4.16)$ \\
\hline \multicolumn{7}{|l|}{ Other relatives } \\
\hline Parental employment & 22 & 2.14 & $0.205^{C}$ & 2 & 0.64 & $0.728^{F}$ \\
\hline Employed & 8 & & $(0.65-7.10)$ & 18 & & $(0.13-3.18)$ \\
\hline \multicolumn{7}{|l|}{ Unemployment } \\
\hline Leading complaints & 11 & 1.99 & $0.158^{C}$ & 12 & 6.23 & $0.000^{c}$ \\
\hline Somatic pain & 19 & & $(0.77-5.14)$ & 8 & & $(2.12-18.35)$ \\
\hline \multicolumn{7}{|l|}{$\begin{array}{l}\text { Other physical } \\
\text { symptoms }\end{array}$} \\
\hline \multirow{2}{*}{$\begin{array}{l}\text { Underlying medical } \\
\text { comorbidity }\end{array}$} & 10 & 1.26 & $0.617^{C}$ & 8 & 1.18 & $0.750^{C}$ \\
\hline & 20 & & $(0.51-3.15)$ & 12 & & $(0.43-3.26)$ \\
\hline \multicolumn{7}{|l|}{ No } \\
\hline No. of medical visits & 2 & 1.23 & $1.000^{F}$ & 4 & 5.75 & $0.038^{F}$ \\
\hline$<6$ times & 28 & & $(0.22-6.73)$ & 16 & & $(1.17-28.27)$ \\
\hline$\geq 6$ times & & & & & & \\
\hline
\end{tabular}

Discussion 
This current study was a preliminary report from Thailand aiming to determine the feasibility of screening for anxiety disorders symptoms in pediatric primary care setting in an Asian country as well as identifying potential and practical clinical clues that may help aiding pediatric health care providers, particularly in hectic pediatric medical setting of Asian countries in recognizing the youths at risk of anxiety disorders presenting with a diverse range of somatic complaints. This study has found that the estimated prevalence of anxiety disorders symptoms in a pediatric primary care setting in Thailand was equal to $39 \%$; and that the female gender had a higher rate of positive anxiety screening, consistent with the prevalence rate reported previously from the studies in medical settings, which were typically much greater than the estimation in community samples $[12,13,28]$.

Interestingly, as a further evaluation of child participants was less likely to take place unless the parents had also endorsed the distressing symptoms in their child, therefore, the rate of attending standard psychiatric evaluation among the child-only screened positive participants was only $25 \%$. This finding may represent the attitude among Thai parents that they regard the internalizing symptoms of their child as a trivial issue. The consequences of the disorders are often invisible to family members, and parents are more likely to seek health services if the symptoms are physical in nature [28-29]. Since parental recognition of anxiety symptoms in their child is an essential element of helping the affected youths to access and acquire evidence-based treatment of the disorders, performing anxiety screening exclusively by child self-report may not enough to facilitate parental awareness of their child's anxiety symptoms particularly in non-Western countries where child mental health literacy and movement is still in their early stage of increasing the public awareness of youth psychological issues. Paired parent-child screening are then recommended due to the higher possibility of the child to receive further comprehensive psychiatric evaluation and proper care.

Educating families about the disorder by providing brief discussion, educational resources, and information about the mental health risk and the benefit of early diagnosis and intervention, could also be a linkage to increase the cognizance of the families under the condition that the parent are also aware of the long-term negative impact of anxiety disorders on their child. Furthermore, frequent medical visits more than 6 times in the past year, and presenting complaints involving somatic pain were also identified as significant associated factors, with the effect size more than 6 times greater than the effect size among the screened negative youths from this current study, similar to the ones reported in previous studies from the US $[12,28]$.

Therefore, frequent medical visits with unexplained somatic pain could be used as an alarming predictor for pediatric primary health care provider to suspect the possibility of anxiety disorders and conduct a more comprehensive screening by SCARED which were also proven as a feasible tool for childhood anxiety disorders symptoms screening in a busy pediatric primary care setting in Thailand from this study.

\section{Conclusion}


Pediatric medical setting has a great potential for improving case identification and treatment delivery for anxiety disorders in the youths. Improving parental recognition and public awareness along with developing a feasible system of brief screening and identification by health care providers in pediatric medical setting seems imperative for youth mental health care in non- Western countries. It is also a critical step toward reducing the burden of unnecessary medical health care utilization and allocating the at-risk youths to proper service direction.

\section{Declarations}

\section{Consent to participate Ethical approval for research involving human participants:}

All procedures performed in studies involving human participants were in accordance with the ethical standards of the ethical committee of Queen Sirikit National Institute of Child Health, and with the 1964 Helsinki declaration and its later amendments or comparable ethical standards. This article does not contain any studies with animals performed by any of the authors. Informed consent in written form was obtained from all individual participants included in the study.

Consent for publication- Not applicable

\section{Authors Contributions:}

Dr. Sirirat Ularntinon conceptualized and designed the study and interpreted data, drafted the initial manuscript, reviewed and revised the manuscript, and approved the final manuscript as submitted.

Dr. Jinjutha Nithiuthai carried out the data collection and management and had full access to all of the data of the study as well as taking responsibility for the integrity of the data and the accuracy of data analysis, and approved the final manuscript as submitted.

Availability of data and materials: The dataset used and analyzed during this current study available from the corresponding author on reasonable request.

Acknowledgement: Not applicable

\section{References}

1. BERNSTEIN G, BORCHARDT C, PERWIEN A. Anxiety Disorders in Children and Adolescents: A Review of the Past 10 Years. Journal of the American Academy of Child \& Adolescent Psychiatry. 1996;35(9):1110-1119. doi:10.1097/00004583-199609000-00008

2. Costello E, Mustillo S, Erkanli A, Keeler G, Angold A. Prevalence and Development of Psychiatric Disorders in Childhood and Adolescence. Arch Gen Psychiatry. 2003;60(8):837. doi:10.1001/archpsyc.60.8.837 
3. Merikangas K, He J, Burstein M et al. Service Utilization for Lifetime Mental Disorders in U.S. Adolescents: Results of the National Comorbidity Survey-Adolescent Supplement (NCS-A). Journal of the American Academy of Child \& Adolescent Psychiatry. 2011;50(1):32-45. doi:10.1016/j.jaac.2010.10.006

4. Hofmann S, Hinton D. Cross-Cultural Aspects of Anxiety Disorders. Curr Psychiatry Rep. 2014;16(6). doi:10.1007/s11920-014-0450-3

5. Furnham A, Hamid A. Mental health literacy in non-western countries: a review of the recent literature. Mental Health Review Journal. 2014;19(2):84-98. doi:10.1108/mhrj-01-2013-0004

6. Campo J, Bridge J, Ehmann M et al. Recurrent Abdominal Pain, Anxiety, and Depression in Primary Care. Pediatrics. 2004;113(4):817-824. doi:10.1542/peds.113.4.817

7. WREN F, BERG E, HEIDEN L et al. Childhood Anxiety in a Diverse Primary Care Population. Journal of the American Academy of Child \& Adolescent Psychiatry. 2007;46(3):332-340. doi:10.1097/chi.0b013e31802f1267

8. Beidel D, Christ M, Long P. Somatic complaints in anxious children. J Abnorm Child Psychol. 1991;19(6):659-670. doi:10.1007/bf00918905

9. Crawley S, Caporino N, Birmaher B et al. Somatic Complaints in Anxious Youth. Child Psychiatry \& Human Development. 2013;45(4):398-407. doi:10.1007/s10578-013-0410-x

10. Last C. Somatic complaints in anxiety disordered children. J Anxiety Disord. 1991;5(2):125-138. doi:10.1016/0887-6185(91)90024-n

11. Jellinek M, Murphy J, Little M, Pagano M, Comer D, Kelleher K. Use of the Pediatric Symptom Checklist to Screen for Psychosocial Problems in Pediatric Primary Care. Arch Pediatr Adolesc Med. 1999;153(3). doi:10.1001/archpedi.153.3.254

12. Chavira D, Stein M, Bailey K, Stein M. Child anxiety in primary care: Prevalent but untreated. Depress Anxiety. 2004;20(4):155-164. doi:10.1002/da.20039

13. Ramsawh H, Chavira D, Kanegaye J, Ancoli-Israel S, Madati P, Stein M. Screening for Adolescent Anxiety Disorders in a Pediatric Emergency Department. Pediatr Emerg Care. 2012;28(10):1041-1047. doi:10.1097/pec.0b013e31826cad6a

14. WREN F, BRIDGE J, BIRMAHER B. Screening for Childhood Anxiety Symptoms in Primary Care: Integrating Child and Parent Reports. Journal of the American Academy of Child \& Adolescent Psychiatry. 2004;43(11):1364-1371. doi:10.1097/01.chi.0000138350.60487.d3

15. Horwitz S, Leaf P, Leventhal J. Identification of Psychosocial Problems in Pediatric Primary Care. Arch Pediatr Adolesc Med. 1998;152(4). doi:10.1001/archpedi.152.4.367

16. Mohapatra S, Agarwal V, Sitholey P, Arya A. A clinical study of anxiety disorders in children and adolescents from North Indian children and adolescents clinic. Asian J Psychiatr. 2014;8:84-88. doi:10.1016/j.ajp.2013.12.005

17. BIRMAHER B, KHETARPAL S, BRENT D et al. The Screen for Child Anxiety Related Emotional Disorders (SCARED): Scale Construction and Psychometric Characteristics. Journal of the American 
Academy of Child \& Adolescent Psychiatry. 1997;36(4):545-553. doi:10.1097/00004583-19970400000018

18. BIRMAHER B, BRENT D, CHIAPPETTA L, BRIDGE J, MONGA S, BAUGHER M. Psychometric Properties of the Screen for Child Anxiety Related Emotional Disorders (SCARED): A Replication Study. Journal of the American Academy of Child \& Adolescent Psychiatry. 1999;38(10):1230-1236. doi:10.1097/00004583-199910000-00011

19. Monga $S$, Birmaher $B$, Chiappetta $L$ et al. Screen for child anxiety-related emotional disorders (SCARED): Convergent and divergent validity. Depress Anxiety. 2000;12(2):85-91. doi:10.1002/15206394(2000)12:2<85::aid-da4>3.0.co;2-2

20. Muris $\mathrm{P}$, Merckelbach $\mathrm{H}$, Kindt $\mathrm{M}$ et al. The utility of screen for child anxiety related emotional disorders (scared) as a tool for identifying children at high risk for prevalent anxiety disorders. Anxiety, Stress \& Coping. 2001;14(3):265-283. doi:10.1080/10615800108248357

21. Hariz N, Bawab S, Atwi M et al. Reliability and validity of the Arabic Screen for Child Anxiety Related Emotional Disorders (SCARED) in a clinical sample. Psychiatry Res. 2013;209(2):222-228. doi:10.1016/j.psychres.2012.12.002

22. Su L, Wang K, Fan F, Su Y, Gao X. Reliability and validity of the screen for child anxiety related emotional disorders (SCARED) in Chinese children. J Anxiety Disord. 2008;22(4):612-621. doi:10.1016/j.janxdis.2007.05.011

23. Weitkamp K, Romer G, Rosenthal S, Wiegand-Grefe S, Daniels J. German Screen for Child Anxiety Related Emotional Disorders (SCARED): reliability, validity, and cross-informant agreement in a clinical sample. Child Adolesc Psychiatry Ment Health. 2010;4(1):19. doi:10.1186/1753-2000-4-19

24. Crocetti E, Hale W, Fermani A, Raaijmakers Q, Meeus W. Psychometric properties of the Screen for Child Anxiety Related Emotional Disorders (SCARED) in the general Italian adolescent population: A validation and a comparison between Italy and The Netherlands. J Anxiety Disord. 2009;23(6):824829. doi:10.1016/j.janxdis.2009.04.003

25. Canals J, Hernández-Martínez C, Cosi S, Domènech E. Examination of a cutoff score for the Screen for Child Anxiety Related Emotional Disorders (SCARED) in a non-clinical Spanish population. J Anxiety Disord. 2012;26(8):785-791. doi:10.1016/j.janxdis.2012.07.008

26. Isolan L, Salum G, Osowski A, Amaro E, Manfro G. Psychometric properties of the Screen for Child Anxiety Related Emotional Disorders (SCARED) in Brazilian children and adolescents. J Anxiety Disord. 2011;25(5):741-748. doi:10.1016/j.janxdis.2011.03.015

27. Dehghani F, Amiri S, Molavi H, Neshat-Doost H. Psychometric properties of the Persian version of the screen for child anxiety-related emotional disorders (SCARED). J Anxiety Disord. 2013;27(5):469-474. doi:10.1016/j.janxdis.2013.06.003

28. Ramsawh H, Chavira D, Stein M. Burden of Anxiety Disorders in Pediatric Medical Settings. Arch Pediatr Adolesc Med. 2010;164(10). doi:10.1001/archpediatrics.2010.170

29. Hughes A, Lourea-Waddell B, Kendall P. Somatic Complaints in Children with Anxiety Disorders and their Unique Prediction of Poorer Academic Performance. Child Psychiatry Hum Dev. 2007;39(2):211- 
220. doi:10.1007/s10578-007-0082-5

Page $12 / 12$ 